\title{
Self-organization in planned Danwei and Dayuan: A case study of the transitional Houzaimen neighborhood of Nanjing in urban China
}

\author{
Qian Zhao \\ Architecture Research Institution, Southeast University, Nanjing, China \\ E-mail: philo_let@hotmail.com
}

\begin{abstract}
The dualism of top-down planning versus self-organization has dominated the paradigm on the evolvement of urban morphology. However, the coexistence of the both can be observed in different scale phenomena, such as the locality of city, states, or even global contexts. In the network of the global economy, urban places as spatial effects of globalization result from negotiations between international capitals and local powers. At the same time, the transitional city form also responds to changing regulations under the state socio-economic regime. Due to economic competitiveness, the entrepreneurial turn in the municipal governance reflects the role shift of local authorities from passive regulation operators to active agents for investment attractiveness and high fiscal incomes. Those changes have particular impacts on city planning while self-organization emerges in urban places. Thus, we study the socioeconomic strata within contemporary urban China's territories to discover dynamics of urban morphology, interacting factors and quantitative signatures for self-organization apart from top-down interventions and finally to reveal the place-shaping mechanism. In the well-reserved Houzaimen neighborhood of Nanjing, the extremely close system- "danwei" and "dayuan" has gradually changed into the new community- "xiaoqu". By site surveys and measurement approaches, the recognized pattern in residential ownerships, the allocation of commercial activities, accessibility and connectivity of residential areas, and fractal distributions in urban fabrics can help to compare self-organizing xiaoqu with planned dayuan for systematic openness and complexity towards sustainability. Meanwhile, dimension spectrum of the fractal structure reveals the mechanism of city evolvement. The result shows the open system fostering self-organization has higher value of fractal dimensions than the segregated one, while it may not necessarily be highly connected "small-world networks". In addition, the identical fractal structure discovered in dayuan proves selforganization can emerge from the planned system.
\end{abstract}

Keywords: top-down planning versus self-organization, danwei and dayuan, Space Syntax, city fractals, the systematic openness.

\section{Introduction}

As a mega-system, city functions with dynamic participants interacting simultaneously (Barthelemy et al., 2013; Batty, 2007). It then brings up a fundamental question on how city evolves into the place where we live every day. Scientists find non-causality in systematic evolvement, which gives a clue to understand the complex system and its evolutive principle, that is, in most circumstances, outside pressures on the system cannot determine its inner behaviors, but stimulate the system to selforganization. Clearly, this pressure-response pattern can refer to top-down planning as the outer force stimulating self-organizational responses. 


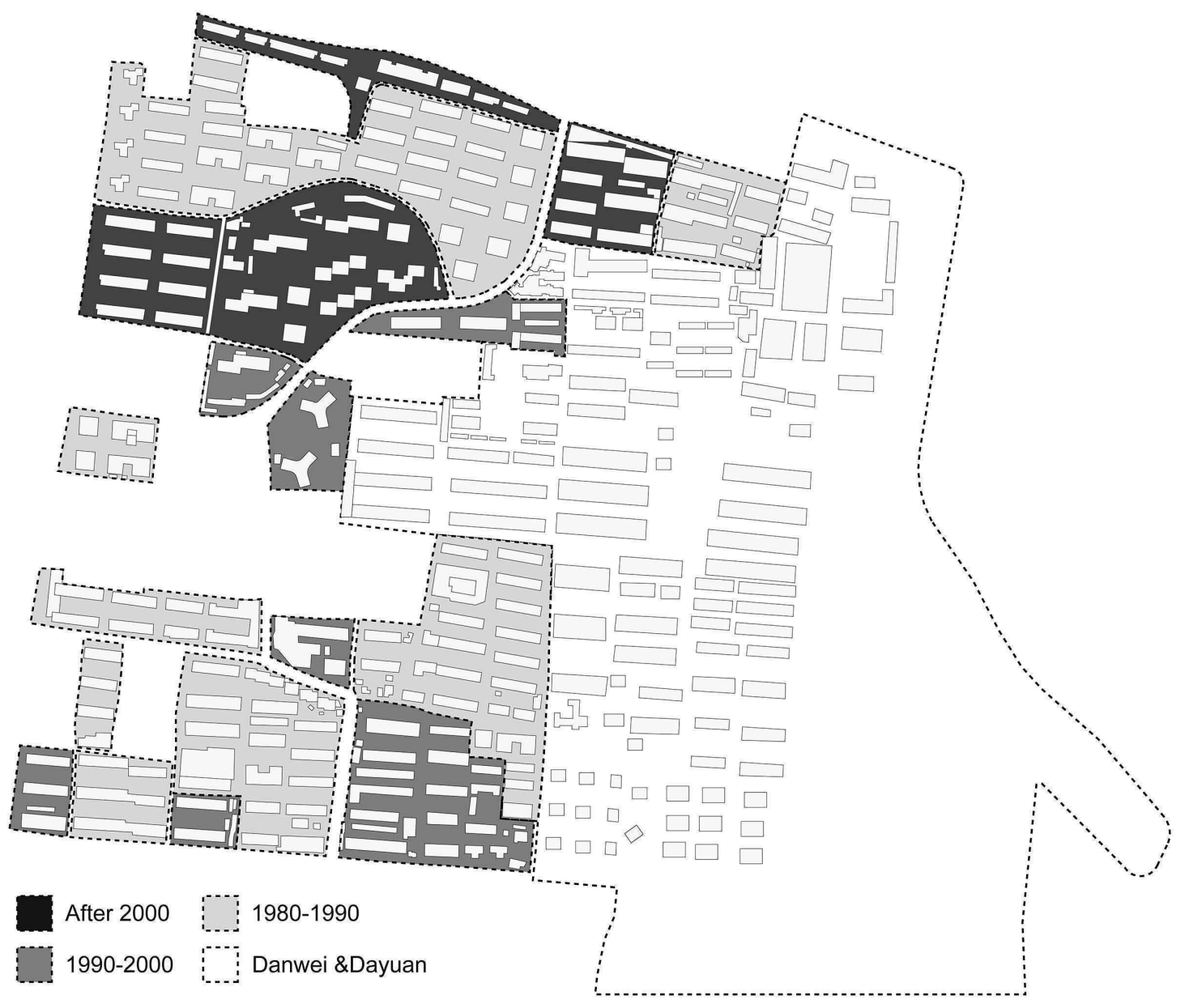

Figure 1.

The changing phases of Houzaimen neighborhood.

Regarded as self-organization, city emerges from its segmental activities (Allen and Sanglier, 1981; Batty, 1995; Portugali, 2000). Ledrut (1968) suggests discontinuous urban morphology in historic cycles has symbolized meanings in both social and cultural aspects. Such spatio-temporal fragments as subcultural mosaics compose dynamic urban society with influx and outflux of population among different regions. Thus, urban places with the presence of globalization have replaced "the duality of national-global” (Sassen 1998).

\section{The study object}

The fragmental space we pick for study purpose has to meet a certain requirements, for instance, a long-term evolutive locality has developed subcultural fabrics in "small-world networks" (Barabási, 2002; Salingaros, 2005). In figure one, Houzaimen neighborhood is divided by residential sections of specific periods shown as colored zones in dashed.

Houzaimen neighborhood stems from danwei system of Mao's era, has survived in social and spatial movements. Varying in functions, "the socialist work unit" (Bray 2005)-danwei and its residential section-dayuan, "a large courtyard" in Chinese term that means "the enclosure or a walled residential compound", consist of residential settlements for staffs, academic and research institutions, military bases with living quarters, etc. As social praxes of multi-origins, danwei and dayuan have carved the contour of urban China. 


\section{The genealogy of danwei system}

As one of socialistic urban theories in early time, "An ideal communist city" written by Soviet scholars, has become the theoretic archetype for real socialist cities and later been adapted to danwei system in urban China. Likewise, influenced by Perry's "the neighborhood unit" (Perry, 1929), the spatial composition of courtyard buildings written in city planning and architectural standards has been applied to dayuan all over the country. Although being part of danwei system, dayuan can exist outside the boundary of danwei.

Under a planned economy favoring the political intervention, such a function-divided entity as danwei with close, reproductive and hierarchical characteristics can find its analogy in a high-modernist planning of 19th century. The latter one has often been recognized for anti-urbanism, i.e. La Ville Radieuse by Le Corbusier, and the reason that causes "fragmentary spaces in urban landscape" (Hillier, 1998) and in result the social segregation in contemporary urban discourses.

\section{The dynamics of urban spatial organization}

Since 1980, China's economy has been activated by top-down reforms implemented in state economic policies. Besides, the booming economy in the next decades has also benefited from the economic globalization and resulted in urban development. The participants identified as local authorities, a free market, and civil society, have played important roles in both social and spatial praxes. Among them, the dominant player is municipal government, who has gradually accommodated its new role in "governmental entrepreneurialism" (Harvey, 1989) motivated by the city land economics, local fiscal incomes and the reform of the revenue sharing between the central government and the local one, and the competitiveness among cities (Friedmann, 2005).

The emergence of a free market has drastically changed the urban economics. In a market economy, the city land has become "a source of incomes" (Vance, 1971). Thus, following the rule of "land-rent gradients" (Vance 1971), the city land economics eventually cause dispersive urban functions with increasing urban population.

Later, state enterprises, private corporations and residential neighborhoods fill in the vacuum of vanishing danwei and dayuan as representatives of the former system, and seek for an expansion. A large amount of inexpensive lands in suburban are rational choices for the new development of research centers, industrial parks, residential settlements, etc, and inevitably result in urban sprawl.

Although driven by different interests, the local government encourages private investments on Central Business Districts as either the recreational version of "city beautiful" or the commercial version of "theme parks", and in return provides supportive policies and munificent compensations for the relocation and urban development.

In civil society, the everyday life has been subordinate to danwei system until social changes and economic reforms take place. After the state law has admitted the ownership of real estates and private properties, the house as a commodity can be traded in and out on the market. As a result, the home trading has dramatically increased in past several decades due to urban migrants attracted by jobs and the social trend towards small family households.

Because of the functionalist zoning plan, the residence has long endured a lack of commodities for basic living conditions within the residential area. Corresponding to the state policy for economic pivot, economic reforms proceed with many state-owned danwei dismissed from national economy, at the same time, private commercial activities are booming. For individuals excluded from danwei system, they have to live on home business in the residential neighborhood.

Later in the neighborhood, grass-rooted movements awakened in company with the commercial campaign for "breaking street walls and opening small business". As a manifesto of the individual against the dominating zoning plan, the phenomena of street-wall business associated with the new residential unit-xiaoqu have turned the courtyard house next to the street wall into mixed-use home business. 
Consequently, the flourishing commercial street in history has recurred with the street door for customers and the owner's house at the rear.

\section{Methodology}

We have already discussed how the transition in urban China happened before with many factors acting simultaneously. As for Houzaimen neighborhood originated from a highly planned economy and commanding society, how does city evolves and sustains in segmental pieces?

The systematic complexity with the naturally formed fractal structure is associated with selforganization towards the open system. Then it brings another question on whether the openness and fractal distributions of urban spaces are correlated to systematic sustainability. Before delving into answers, we have to clarify the definition for self-organization and top-down planning, and then identify self-organizational activities in urban contexts.

Top-down planning versus self-organization

The notion on a planned system with incompatible self-organization reflects the dichotomy of "top-down planning" versus "self-organization" in classic urban theories. Taken as an extreme example, the statical and close system has no room for self-organization, because neither communist society nor laissezfaire economy has compatibility.

In the meantime, self-organization may take place in either planned or market economy, for Chen (2003) suggests that social, political and economic regimes in diversity to some extent have various self-organizational capabilities with a proportional top-down planning in the system. Such ability largely relies on the systematic openness, because only self-organization can exist without topdown interventions. Besides, central planning antithetical to self-organization can be an unnecessary restraint.
The Identification of self-organizing behaviors

The ambiguity in both categories needs to be clarified. We can easily identify high modernist city or villa spontanée, however, the "edge" sometimes blurs in terms of "self-organizing planning" (Portugali, 2000), which is rather part of self-organization than under a planning procedure.

Therefore, the definition for selforganization depends on the scale or urban contexts we discuss. Urban places can be both self-organizing and under the guideline of urban planning. For instance, Houzaimen neighborhood has been constrained by the zoning plan of Nanjing city; likewise, it grows piece by piece at times. Consequently, we see urban spaces as coupling phenomena over a range of scales.

It is also fundamental to identify selforganizing behaviors from interfering forces. For instance, despite being a remote player in local activities, economic globalization derived from massive network effects or environmental exchanges among micro-systems connects a number of localities in the global networks.

Entropy and city evolvement towards sustainability

According to second thermodynamical law, an isolated system will collapse by reaching the maximum entropy. On condition that a well-organizing urban system is open enough to exchange materials, energies and the information with environments, it will reduce the systemic entropy. Therefore, openness for spatial organization will determine systematic sustainability.

Moreover, the self-organizing system known as an organic organization has the fractal structure in common (Mandelbrot, 1983). Fractal dimensions for geometrical fractals also reflect systematic complexity. According as the fractal structure is able to optimize the flux efficiency (Shannon 1948), Bejan and Lorente (2011) prove it maximize the systematic efficiency by the utilization of minimum entropy. Therefore, the system 


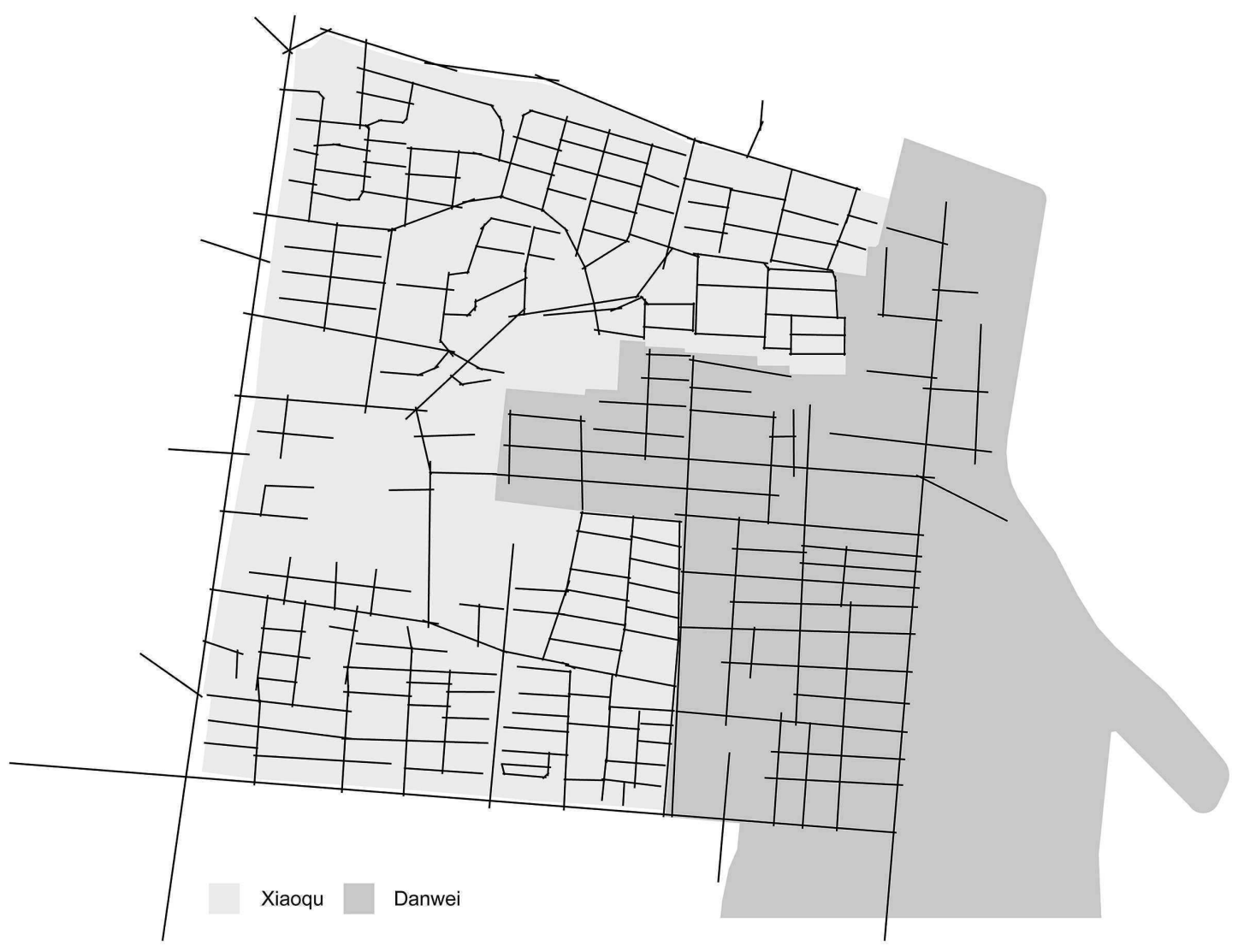

Figure 2.

The axial map of xiaoqu (the light color zone) and danwei (the dark color zone) in Houzaimen neighborhood.

in fractal structure will sustain within its life cycle.

Thus, the "openness" and "fractal distributions" associated with self-organization are two vital elements for sustainable city, and both can be measured by social and spatial parameters.

\section{Measurement and analysis}

The quantitative approaches in the empirical study prove fundamental for social studies and its physical environments. Because multiplex social behaviors often refer its spatial effects to social spatiality or spatialization of social organization, the interconnection we find between human behaviors and physical space will help to measure aggregated human behaviors on condition that physical spaces can be measured. In the following part, the comprehensiveness towards social spatiality is represented by a series of spatial indexes in physical environments.

\section{Universal distance}

The concept of distance has been defined as the length between two points in specific units. Most use the metric units for the measurement of the spatial system. However, "universal distance", based on Bill Hillier (1998), is "a generalization of the idea of depth", which in the graph can be the number of links between two nodes or the number of axial lines as "steps" between one line and another.

In space syntax theory, the invented axial lines as a walkable line define "convex map" of the space. As one of many geometrical properties of the space, "the mathematical definition of convexity" according to Bill Hillier and Julienne Hanson (1984:97), is "no 
tangent drawn on the perimeter passes through the space at any point". The axial map is composed of minimal axial lines throughout the space. The convex units may not be the same, but it is no less than axial lines. In the following study, we neglect the difference between them and treat the both equally.

The openness index

The study has developed an integrative measurement for the open system called "the openness index" based on four hypotheses, which are the allocation of small business, the condition of home trading activities, accessibility and connectivity of residential units in compared areas of dayuan and xiaoqu. The openness index consists of two variables: "human activities in social space" such as commercial activities and "social spatiality" by evaluating urban space accessible to all and interconnected.

The table one shows the deployment of subcultural units based on historic phase and divided by xiaoqu and dayuan. In the chart, except for the existing dayuan in danwei system, most of dayuan built by dissembled danwei back in the 1980s and 1990s have later become xiaoqu by selling residential ownerships to the residents, while the newly developed residential community has come into being after 2000 .

On the one hand, due to the collective ownership, danwei cannot rent or sell its occupied urban lands for commercial purposes. Thus, for dayuan in danwei system, the home trading market only opens when danwei exits. On the other hand, the ownership of properties is essential to systematic accessibility. Opposite to private residential xiaoqu, danwei has claimed itself as public property. Dayuan with security access control barely privileges a certain groups of people. Contrarily, xiaoqu as a private residential property is accessible to all.

\section{Connectivity}

The concept of connectivity embodies two aspects: social networks of human connections can extend globally and function beyond the spatio-temporal reality; in spatial networks, physical links in limited distances are important for everyday life. We only discuss connectivity topologically.

In graph theory, the connectivity index refers to the number of links divided by the number of nodes. Moreover, topological properties of spatial networks will affect the value of connectivity (Zhao, 2017). We apply universal distance to study connectivity, and then the index measures the number of total connectivity of axial lines divided by the number of axial lines. According to Jiang and Claramunt (2002), "the connectivity of an axial line measures the number of lines that directly intersect that given axial line". As a dual map, the axial line and intersection can be translated into the node and link, respectively.

$$
\varepsilon_{\mathrm{L}}=\frac{2 \mathrm{C}_{\mathrm{L}}}{\mathrm{L}}
$$

Both results of connectivity have reached the benchmark for the mesh topology at three (Zhao, 2017), while the value of xiaoqu

Table 1.

Four parameters of the openness index: the street-wall business, home trading activities, accessibility and connectivity.

\begin{tabular}{|c|c|c|c|c|}
\hline residential sections & dayuan & & xiaoqu & \\
\hline years of construction & in danwei system & $1980-2000$ & $1990-2000$ & after 2000 \\
\hline street-wall business & No & Yes & Yes & Yes \\
\hline home trading activities & No & Yes & Yes & Yes \\
\hline accessibility from the public & No & Yes & Yes & Yes \\
\hline connectivity & 3.9 & & 3.0 & \\
\hline
\end{tabular}




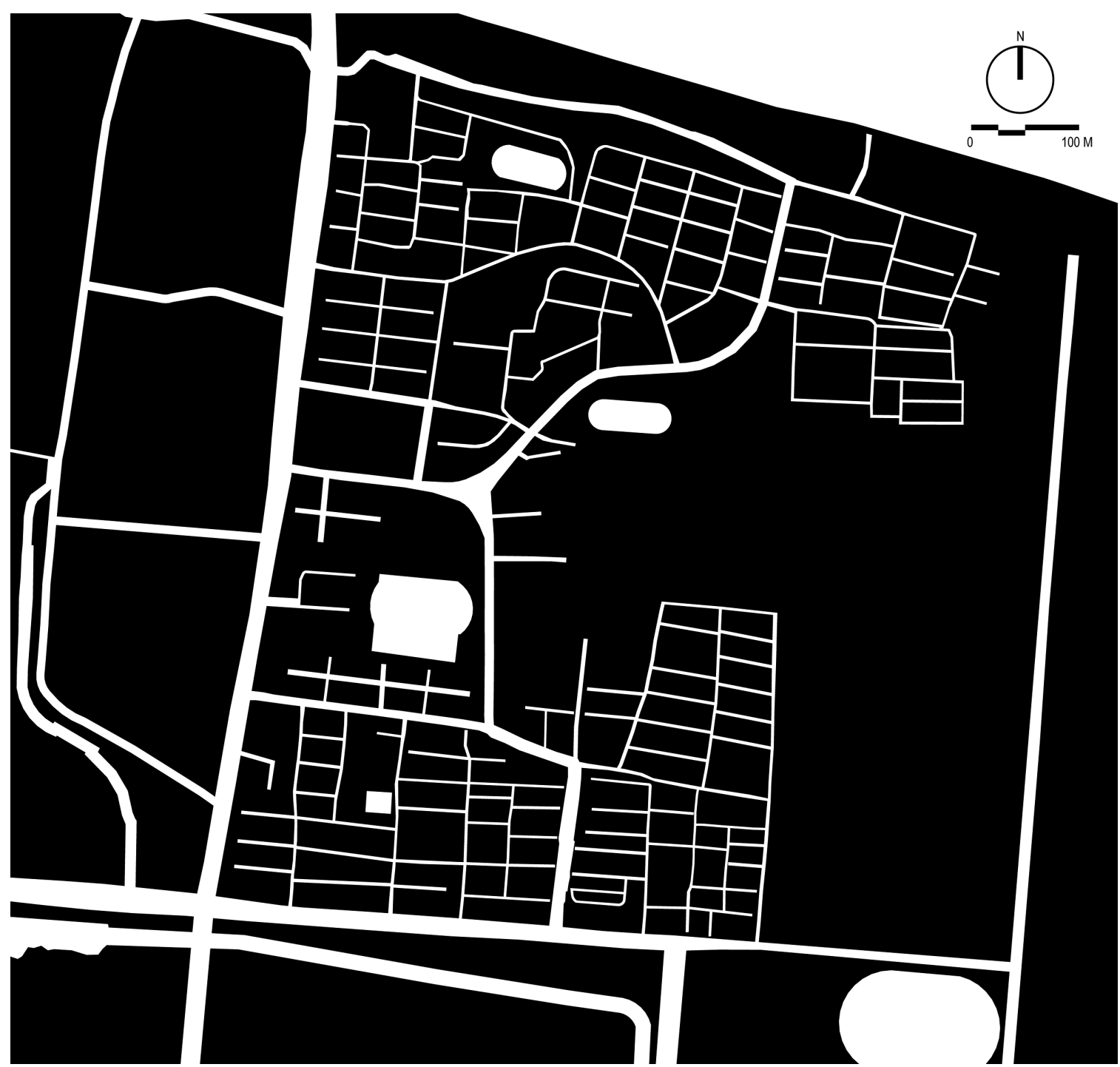

Figure 3.

Urban fabric of xiaoqu in Houzaimen neighborhood that consists of streets and open spaces.

$\left(\varepsilon_{\mathrm{L}}=3.0\right)$ closes to the tree structure without topological rings $\left(\varepsilon_{\mathrm{L}}<3.0\right)$. The topological tree has nodes connected by less links than semilattice with topological rings.

Allen Jacobs (1995) has recorded similar patterns of 'organic cities', but in a large scale, i.e. Ahmadabad in India, Cairo in Egypt, etc. In comparison, such a checkboard road system as dayuan found in ancient Roman cities derived from barracks, colonial cities, or modernist cities can easily fit the difform site and expand to any direction.

As a signature index for topological networks, connectivity seems irrelevant to either self-organizing system or planned one, however, hierarchical tree structure is the typical fractal structure associated with selforganization while the semi-lattice does not have the same attribute.

Given that the system has more access from outside, it will increase inner connectivity, and vice versa. The study shows that the value of connectivity in dayuan $\left(\varepsilon_{\mathrm{L}}=3.9\right)$ is much higher than xiaoqu, and the latter one has more access from the public. We cannot prove the link exists between systematic connectivity and its openness, for the information provided by the connectivity test does not support the argument. Although connectivity may not be the sufficient parameter for the openness index, we can still evaluate the systematic openness by other parameters in social domains. 
City fractals and the inverse power law

As a geometrical approach, the fractal describes "the hierarchical distribution of elements in space" (Frankhauser, 1998). Hence, city fractals (Batty and Longley, 1994; Frankhauser, 1994; Salingaros, 2005) study urban morphology and evolvement on the ground of the fractal theory. Many studies suggest city as the wholeness has only one fractal dimension. According to other authors (Ariza-Villaverde, Jiménez-Hornero and Ravé, 2013), multi-fractal is the nature of urban morphology. Due to the spatiality of city fractals, heterogeneous urban fabrics in different areas, locations, scales, and fractal dimensions are comparable.

Based on the equation for the inverse power law, we can calculate the fractal dimension. For two-dimensional urban fabric, the marginal value is either one or two, which symbolizes a line or a planar graph, respectively. Based on the mathematical definition for dimensions, a complete, planer geometry has the integral dimension of two, while a discrete planer composed by segmental pieces has the fractal dimension below two but above one. According to previous study, the value of 1.5 as a turning point shows the random state of the system, the value under 1.5 reveals the systematic simplification. When the value goes above 1.5 , the system tends to be robustness and complexity.

$$
\mathrm{P}(\mathrm{x})=\mathrm{Ax}^{-\mathrm{m}}(2)
$$

In the distribution map, the sequential variables exhibiting the spatial hierarchy, while the curvefitting reveals the condition of self-organization. Recent urban studies (Salat, Labbé and Nowacki, 2012) have utilized the width of street as the cause factor $\mathrm{x}$ in the function and length of street as distribution of $\mathrm{P}(\mathrm{x})$ to study city fractals based on street networks.

Furthermore, Carvalho and Penn (2004) reveal fractal properties of the axial map. Given that the depth in the axial map replaces the distance in metric units, the connectivity of the axial line and the quantity of lines with the same connectivity can replace the street width and length in the equation, respectively. The

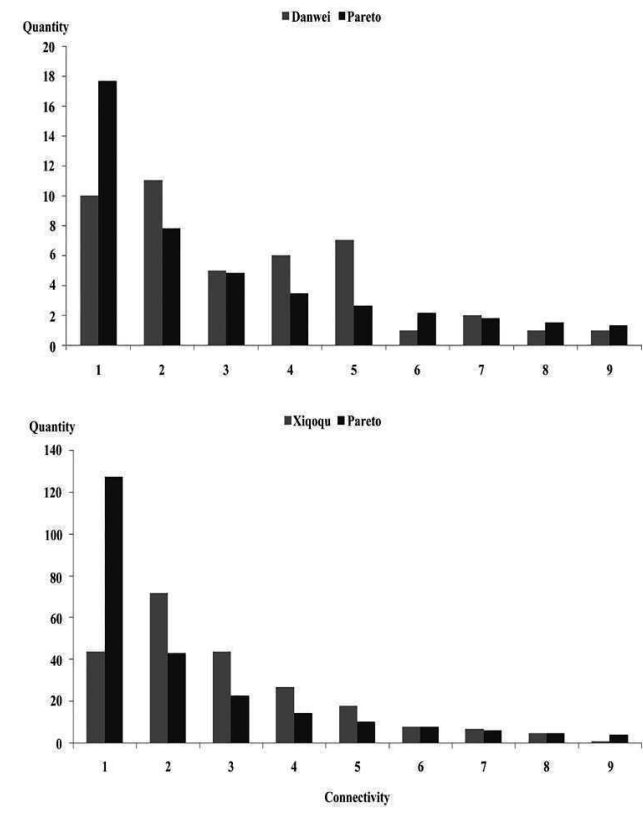

Figure 4.

Pareto distributions (the dark color column) compare with fractal distributions (the light color column) in the same urban area; the connectivity of the axial line is from one to nine. neighborhood that consists of streets and open spaces.

$\mathrm{x}$-axis of coordinates in the following graph presents the connectivity of the axial line and $y$-axis relatively shows the quantity of lines with the same connectivity. The graph tells how spatial fractal distributions of connectivity in actual urban spaces visually match Pareto distributions in different colors.

Based on the initial measure produced by Depthmap program, the connectivity of xiaoqu is from one to thirteen with ten and twelve missing, and for danwei, it is successively from one to eleven, and suddenly jumps to twenty. For comparison purpose, we use the same scale factor $\mathrm{x}$ for both study areas, thus in the following graph, the $\mathrm{x}$-axis only shows connectivity from one to nine.

Because segmental pieces within a certain range of spatial scales compose of urban fabric and the element in smaller scale have a greater probability of quantity based on Pareto distributions, in the equation, the less connectivity is, the more heavily it weighs in fractal distributions. Thus, the missing connectivity in large scale may not significantly affect the result. 


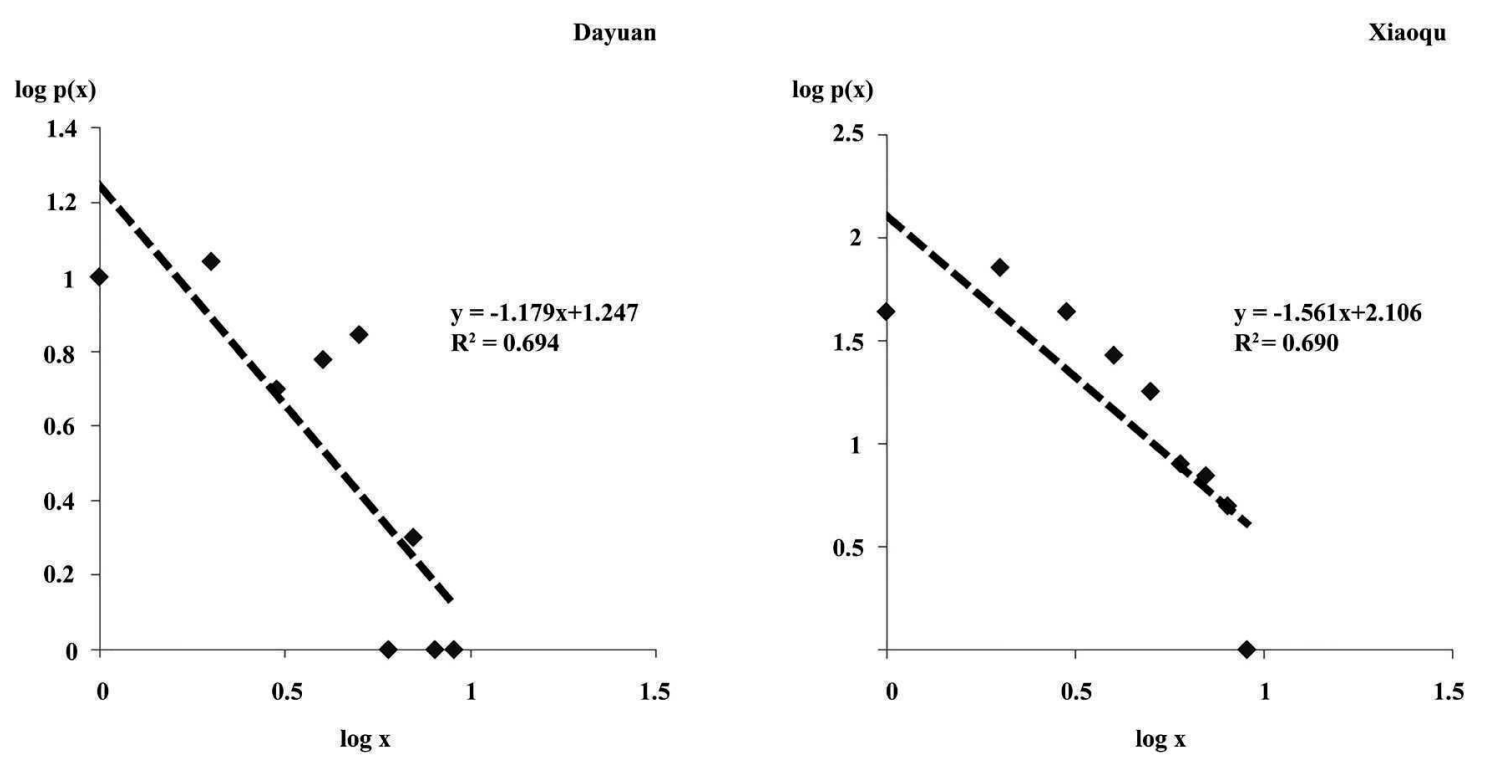

Figure 4.

The comparison of bi-logarithmic regressions between danwei and xiaoqu.

The fractal dimension and bi-logarithmic regression

We apply "a bi-logarithmic regression" (Salat, Labbé, and Nowacki, 2012) to find out the fractal dimension for the potential fractal system. By logarithmically transformed into a function of a linear regression, the coefficient of " $A$ " and the exponential " $\mathrm{m}$ " in the primal equation will be replaced by the constant for $\log (\mathrm{A})$ and the slope of the new function.

The following graph shows that the fractal dimension of dayuan $(\mathrm{m}=1.18)$ is much lower than xiaoqu $(\mathrm{m}=1.56)$, in other words, the latter system is more complex with higher fractal dimension. However, dayuan $(\mathrm{R} 2=.694$, $\mathrm{P}<.001)$ better fits Pareto distributions than xiaoqu $(\mathrm{R} 2=.690, \mathrm{P}<.001)$ does. The result of regression test is seemingly against visual distributions in the previous graph.

Simpson index

By using alternative Simpson index (Salat, Labbé, and Nowacki, 2012), we can measure the degree of heterogeneity in spatial distributions as the variation from Pareto distributions. According to the equation, the lower value of Simpson index results from the less difference between the data in comparison. Given that the city is perfectly geometrical fractals, the value of Simpson index will be zero.

$$
\mathrm{S}=\frac{\sum_{\mathrm{i}=1}^{\mathrm{Cat}}\left(\frac{\mathrm{a}_{\mathrm{j}}-\mathrm{A}}{\mathrm{A}}\right)^{2}}{\text { Cat }}
$$

For the partial fractal structure (connectivity from 1 to 9), xiaoqu $(\mathrm{S}=.395)$ is lower than dayuan $(\mathrm{S}=.454)$, which means in the same structural scale xiaoqu is closer to Pareto distributions. However, the result differs in regression test. Thus, we take connectivity with full range of scales and rerun the test.

For xiaoqu $(\mathrm{m}=1.84, \mathrm{R} 2=.781, \mathrm{P}<.001$ $\mathrm{S}=.485$ ), the whole system is more complex than the part. The contradiction exists in results between the regression test and Simpson index. In the regression test for xiaoqu, the number of R2 increases with a higher fractal dimension while the Simpson index goes to the opposite direction.

In the case of dayuan $(\mathrm{m}=1.08, \mathrm{R} 2=.746$, $\mathrm{P}<.001 \mathrm{~S}=.368$ ), if we eliminate 20 that seems out of scale from the system, the new result $(\mathrm{m}=1.21, \mathrm{R} 2=.759, \mathrm{P}<.001, \mathrm{~S}=.389)$ will show the same pattern as xiaoqu regarding the interrelations between the fractal dimension and its distributions.

In conclusion, we find Simpson index does not work for the fractal distribution test. The result shown in the coefficient of A proves the boundary of xiaoqu is approximately ten 
times of dayuan while the study area in metric units for xiaoqu is almost twice of the latter. For the smaller scale elements, they have higher distributions in the fractal structure. The different study area will significantly affect the value of Simpson index or the regression result, though the curve of Pareto distributions seems smooth in the graph.

\section{Convex space coverage}

In convex map, the basic unit for the axial line defines each convex space. The actual "area"(refers to a universal area) of fractal structure can be measured by the coefficient $\mathrm{A}$ in the equation for the inverse power law, and the area "A" as "fractal area" differs from the study area in metric units. The density of the fractal area equals the reciprocal of convex space coverage, which are:

$$
\text { convex space coverage }=\frac{\text { Convex Space }}{\text { Fractal Area }}(4)
$$

The high value of convex space coverage represents a less integral or segmental system. The index can eliminate the variation of the study area that affects the result of regression test. We find the fractal dimension has statistical significant correlation with convex space coverage $(\mathrm{R}=0.98, \mathrm{p}<0.001)$.

\section{Conclusion}

The study identifies three facets for city evolvement, which are "participants", "mechanism" and "sustainability". The "sustainability" is an ultimate goal for the existent including city forms. Self-organization as the crucial "participant" in sustainable urban morphology causes the system in fractal structures to be open. Besides, the "mechanism" of city evolvement can find its quantitative signature in fractal dimensions.

Sustainable city form: the openness and fractal distributions

Self-organization is the key element for systematic sustainability. We find both social and spatial proofs in the openness index and fractal distributions of urban fabrics. In terms of the openness index, the anticipated social spatiality can be detected in comparable urban fabrics: self-organizing xiaoqu is more open than planned dayuan. We also find low value of connectivity of topological tree structure in the self-organizing system rather than hierarchically social space. Although the social logic can explain such spatial consequences, the network of self-organizing system does not require the highest connections within the system, and instead, it always finds the most efficient way in self-connection as the part of self-organizing process and in result the fractal structure.

Fractal distributions as optimal structure are close to Pareto distributions. We discover the contradictions in test results by different approaches. As a result, Simpson index does not work for the evaluation of fractal distributions. Because the regression test shows that selforganization exists in the planned system, we can develop two possible arguments as follow. First, the result is null for the fractal structure is independent of self-organization. In fact, the fractal structure results from selforganization. The second argument that dayuan is self-organizing system also violates its social formation. Otherwise, the only logic conclusion is that the dayuan system is not only spatially self-organizing but also socially planned.

Table 2. Fractal distributions and related index: fractal area, fractal dimension, regression square, Simpson index, and convex space coverage.

\begin{tabular}{ccccccc}
\hline & & $\begin{array}{c}\text { fractal } \\
\text { area }\end{array}$ & $\begin{array}{c}\text { fractal } \\
\text { dimension }\end{array}$ & $\begin{array}{c}\mathrm{R}^{2} \\
\mathrm{p}<.001\end{array}$ & $\begin{array}{c}\text { Simpson } \\
\text { index }\end{array}$ & $\begin{array}{c}\text { convex space } \\
\text { coverage }\end{array}$ \\
\hline xiaoqu & the full scale & 167.88 & 1.84 & .781 & .485 & 1.36 \\
$354,538 \mathrm{~m}^{2}$ & the part of scale & 127.64 & 1.56 & .690 & .395 & 1.77 \\
\hline \multirow{2}{*}{ dayuan } & the full scale & 15.49 & 1.08 & .746 & .368 & 3.03 \\
$201,343 \mathrm{~m}^{2}$ & the adjusted scale & 18.07 & 1.21 & .759 & .389 & 2.55 \\
& the part of scale & 17.66 & 1.18 & .694 & .454 & 2.49 \\
\hline
\end{tabular}


Although a rarely close system-dayuan starts under a top-down planning, it has long evolved into spatial-beings in dynamic urban contexts.

Systematic complexity and mechanism of city evolvement

The fractal dimension can measure the systematic complexity. We find that as the fractal structure self-organizing xiaoqu is far more complex than planned dayuan, likewise an integral system is also more complex than the part. Our research on fractal dimensions of heterogeneous urban fabrics proves that the statical mono-fractal does not exist in urban spaces. When the simply planned system $(\mathrm{m}<1.5)$ has evolved towards complexity $(\mathrm{m}>1.5)$, it inevitably goes to chaos with selforganization emerging in segments (the fractal dimension closes to 1.5).

In addition, there is no statistically significant correlation between the fractal dimension and fractal distributions $(\mathrm{R}=0.27, \mathrm{p}<0.05)$. When we rule out the unreliable data from results, the tendency of these two indexes can be identical within the individual system, but it lacks of the sufficient proofs due to limited data. In conclusion, there is no significant link between systematic complexity and self-organization. The fractal structure only exists in selforganization no matter whether the system is complex or not, in other words, it lives through all phases of urban morphology.

\section{References}

Allen, P.M. and Sanglier, M. (1981) 'Urban evolution, self-Organization, and decisionmaking', Environment and Planning A 13(2), 167-83.

Ariza-Villaverde, A.B., Jiménez-Hornero, F.J. and Ravé, E.G.D. (2013) 'Multifractal analysis of axial maps applied to the study of urban morphology', Computers, Environment and Urban System 38, 1-10.

Barabási a. L.(2002) Linked: the new science of networks (Perseus Publishing, Cambridge).

Barthelemy, M., Bordin, P., Berestycki, H. and Gribaudi, M. (2013) 'Self-organization versus top-down planning in the evolution of a city', Scientific Reports 3(1).

Batty, M. and Longley, P. (1994) Fractal cities (Academic Press, London).

Batty, M. (1995) 'New ways of looking at cities', Nature 377(6550), 574.

Batty, M. (2007) Cities and complexity (MIT Press, Cambridge).

Bray, D. (2005) Social space and governance in urban china (Stanford University Press, Stanford).

Bejan, A. and Lorente, S. (2011) 'The constructal law of design and evolution in nature', Physics Life Review 8, 209-40.

Carvalho, R. and Penn, A. (2004) 'Scaling and university in the micro-structure of urban space', Physica A332, 539-47.

Chen, Y.G. (2003)'Self-organization and selforganizing cities', City Planning Review 27(10), 17-22.

Frankhauser, P. (1994) La Fractalité des Structures Urbaines (Anthropos, Paris).

Frankhauser, P. (1998) 'The fractal approach: A newtool for the spatial analysis of urban agglomerations', Population: An English Selection 10(1), 205-40.

Friedmann, J. (2005) China's urban transition (University of Minnesota Press, Minnesota).

Harvey, D. (1989) 'From managerialism to entrepreneurialism: the transformation in urban governance in late capitalism', in Bridge, G. and Watson, S. (eds.) The Blackwell city readers (Blackwell Publishing, Oxford) 456-63.

Hillier, B. (1998) Space is the machine (Cambridge University Press, Cambridge).

Jacob, A. B. (1995) Great streets (MIT Press, Cambridge).

Ledrut, R. (1968) Sociologie urbaine (R.U.F., Paris).

Mandelbrot, B.B. (1983) The fractal geometry of nature (W.H. Freeman, San Francisco).

Perry, C.A. (1929) 'The neighborhood unit', Regional New York and Its Environs 7.

Portugali, J. (2000) Self-organization and the city (Springer-Verlag, Berlin).

Salat, S., Labbé, F., and Nowacki, C. (2012) Cities and forms (China's Architectural Industry Press, Beijing).

Salingaros, N.A. (2005) Principles of urban structure (Techne Press, Amsterdam).

Sassen, S. (1998) The globalization and its 
discontents (New Press, New York).

Shannon, C.E. (1948) 'A mathematical theory of communication', Bell System Technical Journal 27, 379-43.

Vance, J.E., Jr. (1971) 'Land assignment in the precapitalist, capitalist, and postcapitalist city', Economic Geography 47,101-20.

Zhao, Q. (2017) 'Towards sustainable urbanism: the urban spatial organization and a measurement approach from origins to transition', unpublished $\mathrm{PhD}$ thesis, Southeast University, China.

Paris, France: Hermann.

Talen, E. (2012). City rules: How regulations affect urban form. Island Press.

Zhao Y.(2011) The Institutional Genes of Urban Landscape. Time+Architecture, 3:1013. 